\title{
Risk factors and time to symptomatic presentation in leukaemia, lymphoma and myeloma
}

\author{
Debra A Howell ${ }^{\star}, 1$, Fiona Warburton ${ }^{2}$, Amanda-Jane Ramirez ${ }^{2}$, Eve Roman ${ }^{1}$, Alexandra G Smith ${ }^{1}$ \\ and Lindsay J L Forbes ${ }^{2}$ \\ ${ }^{1}$ Epidemiology and Cancer Statistics Group, Department of Health Sciences, University of York, York YO10 5DD, UK and ${ }^{2}$ Kings \\ College London Promoting Early Cancer Presentation Group, 4th Floor, Capital House, 42, Weston Street, London SE1 3QD, UK
}

Background: UK policy aims to improve cancer outcomes by promoting early diagnosis, which for many haematological malignancies is particularly challenging as the pathways leading to diagnosis can be difficult and prolonged.

\begin{abstract}
Methods: A survey about symptoms was sent to patients in England with acute leukaemia, chronic lymphocytic leukaemia (CLL), chronic myeloid leukaemia (CML), myeloma and non-Hodgkin lymphoma (NHL). Symptoms and barriers to first help seeking were examined for each subtype, along with the relative risk of waiting $>3$ months' time from symptom onset to first presentation to a doctor, controlling for age, sex and deprivation.
\end{abstract}

Results: Of the 785 respondents, 654 (83.3\%) reported symptoms; most commonly for NHL (95\%) and least commonly for CLL (67.9\%). Some symptoms were frequent across diseases while others were more disease-specific. Overall, $16 \%$ of patients $(n=114)$ waited $>3$ months before presentation; most often in CML (24\%) and least in acute leukaemia (9\%). Significant risk factors for $>3$ months to presentation were: night sweats (particularly CLL and NHL), thirst, abdominal pain/discomfort, looking pale (particularly acute leukaemias), and extreme fatigue/tiredness (particularly $\mathrm{CML}$ and $\mathrm{NHL}$ ); and not realising symptom(s) were serious.

Conclusions: These findings demonstrate important differences by subtype, which should be considered in strategies promoting early presentation. Not realising the seriousness of some symptoms indicates a worrying lack of public awareness.

Cancer outcomes in England are poorer than European averages and this is considered to be due, at least in part, to diseases being identified at a late stage as a consequence of delayed diagnosis (Richards, 2009). Promotion of early diagnosis is therefore a central tenet of the UK Department of Health's strategy, the overarching aim being to align UK survival rates with the best in Europe (Department of Health, 2011a). A range of interventions to promote early diagnosis have been introduced in the United Kingdom (including guidelines, targets and education campaigns) (Department of Health, 2000; NICE, 2005). These have had a mixed impact, however (Peacock et al, 2013; Neal et al, 2014), and as many as a quarter of people are still diagnosed with cancer after emergency presentation to secondary care (Elliss-Brookes et al, 2012), a route often associated with prolonged time to diagnosis, advanced stage disease and poorer survival (McPhail et al, 2013).

Collectively, haematological malignancies are common, being the fourth most frequently diagnosed cancer in both males and females in economically developed regions of the world (Jemal et al, 2008; Westlake, 2008; Ferlay et al, 2010). Traditionally categorised into four main groups (leukaemias, Hodgkin lymphomas, non-Hodgkin lymphomas (NHLs) and myeloma), these complex cancers actually comprise $>60$ different subtypes, each exhibiting different patterns of onset, progression, management and survival (Swerdlow et al, 2008). Issues relating to early diagnosis are particularly pertinent in these diseases as, compared with many other cancers, the pathway leading to diagnosis can be

*Correspondence: Dr DA Howell; E-mail: debra.howell@york.ac.uk

Received 30 April 2015; revised 2 July 2015; accepted 5 August 2015; published online 1 September 2015 
difficult and prolonged. These diseases are, for example, often associated with variable symptoms, prolonged time to help seeking, multiple primary care consultations before referral to secondary care, diverse referral pathways and an increased risk of being diagnosed after emergency presentation (Allgar and Neal, 2005; Howell et al, 2006, 2007, 2013; Department of Health, 2011b; Elliss-Brookes et al, 2012; Lyratzopoulos et al, 2012).

Further evidence-based understanding about factors impacting on the time taken to diagnose these cancers, and identification of means of facilitating and ensuring prompt diagnosis is therefore of particular importance. In 2011, a study was carried out in England, which aimed to examine time taken for patients' to present to a doctor and seek help for a number of different cancers, including several haematological malignancy subtypes (Forbes et al, 2014). This study focused on risk factors (including symptoms and barriers to help seeking) associated with patients' waiting $>3$ months before help seeking. The current paper describes detailed findings from this study, specifically focusing on the haematological malignancies, presenting data on a wider range of subtypes, focusing on symptoms that are known to be common in these diseases and examining barriers that may be specific to these cancers.

\section{MATERIALS AND METHODS}

The patients included in this paper are a subset of people who participated in the 2010 National Cancer Patient Experience Survey (NCPES) (Department of Health, 2010). This survey was distributed in England to all cancer patients (aged $\geqslant 16$ years) receiving care across 158 NHS Trusts as day cases or in-patients, January to March inclusive, 2010. A total of 67713 patients responded (67\%); and 53104 agreed they could be re-contacted for further research purposes, including 5925 with haematological malignancies. This group comprised patients with acute leukaemia (acute lymphoblastic-ICD-10 C91.0 and acute myeloid-ICD-10 C92.0), chronic lymphocytic leukaemia (CLL, ICD-10 C91.1), chronic myeloid leukaemia (CML, ICD-10 C92.1) multiple myeloma (ICD-10 C90) and NHL (ICD-10 C82-83).

For a number of different cancers, a further questionnaire was then mailed to a subset of patients, examining time to presentation and risk factors for waiting $>3$ months before first presentation to a doctor. In accordance with the Aarthus statement (Weller et al, 2012), this time period includes the appraisal interval, which is when the first symptoms or bodily changes are noticed by the patient, and the help seeking interval, which is the time taken to interpret the symptoms and/or changes and seek help. A time period of $>3$ months was used to indicate prolonged time to diagnosis as this has previously been found to have clinical importance (Richards et al, 1999). The additional questionnaire was sent to 200 patients randomly selected from each of the haematological disease groups listed above; and it is these findings which are the focus of the present paper.

Detailed information about the methods used in the second survey have already been published (Forbes et al, 2014). The survey instrument was a self-completed questionnaire; patients were asked to identify the symptom(s) that had caused them to see a doctor and led to their diagnosis from a predefined list (devised with clinical haematology experts). Patients were also asked to indicate the duration of time that had passed between first noticing the symptom(s) that led to diagnosis and presenting to a doctor $(\leqslant 4$ weeks, 4 weeks to 3 months and $>3$ months), the date of onset of the presenting symptom(s) and the date of their first appointment with a doctor. Finally, participants were asked to report what (if anything) had put them off seeing a doctor. The questionnaire was distributed between November 2011 and January 2012, and two reminders were sent to non-responders.
Duration of symptoms was calculated based on the time that had passed between first noticing the symptoms that led to diagnosis and presenting to a doctor. If this information was not available, the first symptom that had both date of symptom onset and date of first doctor's appointment was used. Area-based measures of deprivation were sourced from national data, the Index of Multiple Deprivation (IMD) being used to categorise individuals into quintiles (one to five): quintile one being the most affluent and quintile five the least (Public Health Observatory, 2011). Relative risks (with 95\% confidence intervals) were calculated for time to presentation of $>3$ months by subtype, presenting symptoms and any reason for putting off going to the doctor. Age, sex and deprivation category were controlled for owing to the possibility that these might influence time to diagnosis (Ramirez et al, 1999; Macleod et al, 2009).

The NCPES reported perceptions of NHS patient care and was designed to improve services, so ethics approval was not sought. All patients had, however, consented to being approached again for further research purposes.

\section{RESULTS}

Completeness of sample and response. Of the 5925 patients with haematological cancers who participated in the 2010 NCPES and agreed they could be contacted again for further research, 4820 $(81.4 \%)$ were alive in November 2011. As expected, the proportion alive varied by diagnostic group, ranging from $89.3 \%$ among patients with CML to $68.1 \%$ in those with acute leukaemia. Of the 1000 individuals sent the survey (200 from each group), a total of 785 patients $(79.4 \%)$ completed and returned the questionnaire, and there was little variation in response by diagnostic subtype (Table 1).

Participants. Patients were diagnosed at various time intervals prior to participation in the NCPES in 2010. All patients with CLL, myeloma and NHL were diagnosed in the year before the survey, along with $90 \%$ of patients with acute leukaemia and 36\% with CML. Ten percent of patients with acute leukaemia and $44 \%$ with CML were diagnosed 1-5 years before the survey; and 20\% with CML were diagnosed $>5$ years before.

The average age of participants was 58 years (range 14-84), and those with acute leukaemia and CML were younger than the remaining groups (53 years, range $14-80$ and 52 years, range 2280 , respectively). The vast majority of participants (95.4\%) were of white ethnic origin and a larger proportion were from IMD quintile one (25.8\%) than quintile five (13\%).

\begin{tabular}{|c|c|c|c|c|c|}
\hline & & \multicolumn{4}{|c|}{$\begin{array}{ccc}\text { Patents alive } & \text { Responded to } \\
\text { in November } & \text { survey }(n=200 \\
2011 & \text { per subtype) }\end{array}$} \\
\hline ICD-10 & Cancer type & $N$ & (\%) & $N$ & (\%) \\
\hline C92.1 & $\begin{array}{l}\text { Chronic myeloid } \\
\text { leukaemia (CML) }\end{array}$ & 218 & (89.3) & 159 & $(79.5)$ \\
\hline C82-83 & $\begin{array}{c}\text { Non-Hodgkin } \\
\text { lymphoma (NHL) }\end{array}$ & 1730 & $(87.5)$ & 161 & (80.9) \\
\hline C91.1 & $\begin{array}{c}\text { Chronic lymphocytic } \\
\text { leukaemia (CLL) }\end{array}$ & 700 & $(82.1)$ & 161 & $(80.5)$ \\
\hline $\mathrm{C9O}$ & Myeloma & 1695 & $(78.8)$ & 150 & $(76.1)$ \\
\hline C91.0, C92.0 & Acute leukaemia & 477 & $(68.1)$ & 154 & $(80.2)$ \\
\hline & Total & 4820 & (81.4) & 785 & (79.4) \\
\hline
\end{tabular}


What were the symptoms that led to a diagnosis of cancer? Of the 785 patients who returned a questionnaire, 654 reported at least one symptom (83.3\%) (Table 2). Presence or absence of symptoms varied by diagnostic group; patients with NHL were most likely to report symptoms (95\%), followed by those with acute leukaemia (91.6\%), CML (83.2\%), myeloma (78.7\%) and CLL (67.9\%).

Similarities and differences in symptoms were identified between disease subtypes. Across all diagnoses, systemic symptoms were most common (particularly extreme fatigue/tiredness, unusual sweating at night, unexpected weight-loss and pallor), followed by pain, chest problems, lymphadenopathy and bleeding. Looking more specifically within the systemic symptoms, extreme fatigue/tiredness was particularly apparent among patients with acute leukaemia (70.9\%) and CML (61.2\%), and unusual night sweats was most common in patients with CML (39.6\%) and CLL (35.2\%).

As expected, symptoms became increasingly disease specific beyond this: pallor and bruising/bleeding was most commonly associated with the acute leukaemias; abnormal lumps were the most common symptom in CLL and NHL, along with abdominal discomfort; and bone pain/discomfort was the most frequent symptom of myeloma. Although pain was the most common symptom reported for myeloma (77.1\%), it was also frequently reported in other diseases, including CML (49.3\%), NHL (30.1\%), acute leukaemia (29.1\%) and CLL (20.4\%). A plethora of additional symptoms were noted, including unusual itching, fever and thirst.

What put you off going to the doctor? Of the 654 patients with symptoms, $380(58.1 \%)$ reported a reason for putting off going to the doctor (Table 3 ), and there was marked variation by diagnostic group. Patients with CML were most likely to report reasons (90.3\%), followed by acute leukaemia (68.1\%), NHL (47.7\%), myeloma (43.2\%) and CLL (36.1\%). Overall, a third of patients with symptoms (218/654) said they did not seek medical help earlier because they did not realise their symptoms were serious, most commonly patients with CML (47\%) and acute leukaemia (39.7\%).

Of patients who said they had not realised that their symptoms were serious, the most commonly reported problems were fatigue, bleeding and shortness of breath in acute leukaemia; fatigue, lump and shortness of breath in CLL; fatigue, night sweats and weight loss in CML; bone pain and fatigue in myeloma; and fatigue, lump and shortness of breath in NHL.

How long was it from noticing symptoms to first seeing a doctor? Of patients reporting at least one symptom, 91\% $(n=597)$ had data available on duration of symptoms, and this ranged from $81 \%$ in CLL to $95 \%$ in both NHL and CML. Overall, $16 \%(n=104)$ of patients waited $>3$ months before

Table 2. Symptoms ${ }^{a}$ reported by 654 patients with at least one symptom, by diagnosis

\begin{tabular}{|c|c|c|c|c|c|c|}
\hline & Total & Acute leukaemiab & CLL & CML & Myeloma & NHL \\
\hline Total patients & $785(100)$ & $154(100)$ & $159(100)$ & $161(100)$ & $150(100)$ & $161(100)$ \\
\hline Total patients with symptoms & $654(83.3)$ & $141(91.6)$ & $108(67.9)$ & $134(83.2)$ & $118(78.7)$ & $153(95.0)$ \\
\hline Systemic symptoms ${ }^{c}$ & $404(61.2)$ & $112(79.4)$ & $67(62.0)$ & $102(76.1)$ & $62(52.5)$ & $61(39.9)$ \\
\hline $\begin{array}{l}\text { Extreme fatigue or tiredness } \\
\text { Unusually pale } \\
\text { Unusual sweating at night } \\
\text { Unexpected weight loss } \\
\text { Nausea } \\
\text { Faint or dizzy } \\
\text { Loss of appetite }\end{array}$ & $\begin{aligned} 332 & (50.8) \\
96 & (14.7) \\
154 & (23.5) \\
125 & (19.1) \\
5 & (0.8) \\
8 & (1.2) \\
2 & (0.3)\end{aligned}$ & $\begin{aligned} 100 & (70.9) \\
45 & (31.9) \\
26 & (18.4) \\
18 & (12.8) \\
1 & (0.7) \\
0 & (0.0) \\
1 & (0.7)\end{aligned}$ & $\begin{array}{c}52(48.1) \\
17(15.7) \\
38(35.2) \\
20(18.5) \\
1(0.9) \\
3(2.8) \\
0(0.0)\end{array}$ & $\begin{array}{l}82(61.2) \\
19(14.2) \\
53(39.6) \\
43(32.1) \\
0(0.0) \\
2(1.5) \\
0(0.0)\end{array}$ & $\begin{aligned} 51 & (43.2) \\
10 & (8.5) \\
12 & (10.2) \\
20 & (16.9) \\
2 & (1.7) \\
0 & (0.0) \\
0 & (0.0)\end{aligned}$ & $\begin{aligned} 47 & (30.7) \\
5 & (3.3) \\
25 & (16.3) \\
24 & (15.7) \\
1 & (0.7) \\
3 & (2.0) \\
1 & (0.7)\end{aligned}$ \\
\hline Pain symptoms ${ }^{c}$ & $266(40.7)$ & $41(29.1)$ & $22(20.4)$ & $66(49.3)$ & $91(77.1)$ & $46(30.1)$ \\
\hline $\begin{array}{l}\text { Pain or discomfort in bones } \\
\text { Pain or discomfort in tummy } \\
\text { Other pain }\end{array}$ & $\begin{array}{c}181(27.7) \\
108(16.5) \\
11(1.7)\end{array}$ & $\begin{array}{c}34(24.1) \\
17(12.1) \\
1(0.7)\end{array}$ & $\begin{aligned} 14 & (13.0) \\
9 & (8.3) \\
2 & (1.9)\end{aligned}$ & $\begin{array}{c}30(22.4) \\
41(30.6) \\
6(4.5)\end{array}$ & $\begin{aligned} 87 & (73.7) \\
8 & (6.8) \\
0 & (0.0)\end{aligned}$ & $\begin{array}{c}16(10.5) \\
33(21.6) \\
2(1.3)\end{array}$ \\
\hline Chest symptoms $^{c}$ & $232(35.5)$ & 76 (53.9) & $46(42.6)$ & $49(36.6)$ & $26(22.0)$ & 35 (22.9) \\
\hline $\begin{array}{l}\text { Shortness of breath } \\
\text { Lots of coughs and colds } \\
\text { Sore throat }\end{array}$ & $\begin{array}{c}173(26.5) \\
99(15.1) \\
9(1.4)\end{array}$ & $\begin{array}{c}56(39.7) \\
29(20.6) \\
6(4.3)\end{array}$ & $\begin{aligned} 37 & (34.3) \\
22 & (20.4) \\
1 & (0.9)\end{aligned}$ & $\begin{array}{c}31(23.1) \\
24(17.9) \\
0(0.0)\end{array}$ & $\begin{aligned} 22 & (18.6) \\
6 & (5.1) \\
0 & (0.0)\end{aligned}$ & $\begin{array}{c}27(17.6) \\
18(11.8) \\
2(1.3)\end{array}$ \\
\hline Lump $^{c}$ & $160(24.5)$ & $5(3.5)$ & $57(52.8)$ & $8(6.0)$ & $5(4.2)$ & $85(55.6)$ \\
\hline $\begin{array}{l}\text { Lump in neck, groin or armpit } \\
\text { Lump/swelling in tummy } \\
\text { Other lump }\end{array}$ & $\begin{array}{l}139(21.3) \\
10(1.5) \\
14(2.1)\end{array}$ & $\begin{array}{l}4(2.8) \\
0(0.0) \\
1(0.7)\end{array}$ & $\begin{aligned} 56 & (51.9) \\
1 & (0.9) \\
0 & (0.0)\end{aligned}$ & $\begin{array}{l}1(0.7) \\
6(4.5) \\
2(1.5)\end{array}$ & $\begin{array}{l}0(0.0) \\
2(1.7) \\
3(2.5)\end{array}$ & $\begin{array}{c}78(51.0) \\
1(0.7) \\
8(5.2)\end{array}$ \\
\hline Bleeding symptoms ${ }^{c}$ & $126(19.3)$ & $51(36.2)$ & $16(14.8)$ & $35(26.1)$ & $15(12.7)$ & $9(5.9)$ \\
\hline $\begin{array}{l}\text { Unusual bruising, rash/red spots } \\
\text { Unusual bleeding } \\
\text { Black stool }\end{array}$ & $\begin{array}{l}96(14.7) \\
49(7.5) \\
3(0.5)\end{array}$ & $\begin{array}{c}42(29.8) \\
22(15.6) \\
0(0.0)\end{array}$ & $\begin{aligned} 12 & (11.1) \\
4 & (3.7) \\
1 & (0.9)\end{aligned}$ & $\begin{array}{l}26(19.4) \\
13(9.7) \\
2(1.5)\end{array}$ & $\begin{array}{l}9(7.6) \\
8(6.8) \\
0(0.0)\end{array}$ & $\begin{array}{l}7(4.6) \\
2(1.3) \\
0(0.0)\end{array}$ \\
\hline \multicolumn{7}{|l|}{ Other symptoms ${ }^{c}$} \\
\hline $\begin{array}{l}\text { Fever } \\
\text { Skin unusually itchy } \\
\text { Unusually thirsty } \\
\text { Skin went yellow } \\
\text { Headache } \\
\text { Oral symptoms } \\
\text { Swollen leg } \\
\text { Visual problems } \\
\text { Bowel symptoms }\end{array}$ & $\begin{aligned} 34 & (5.2) \\
51 & (7.8) \\
33 & (5.0) \\
14 & (2.1) \\
9 & (1.4) \\
3 & (0.5) \\
11 & (1.7) \\
4 & (0.6) \\
11 & (1.7)\end{aligned}$ & $\begin{aligned} & 15(10.6) \\
& 14(9.9) \\
& 5(3.5) \\
& 6(4.3) \\
& 4(2.8) \\
& 2(1.4) \\
& 1(0.7) \\
& 1(0.7) \\
& 0(0.0)\end{aligned}$ & $\begin{aligned} & 2(1.9) \\
12 & (11.1) \\
7 & (6.5) \\
4 & (3.7) \\
0 & (0.0) \\
0 & (0.0) \\
2 & (1.9) \\
0 & (0.0) \\
1 & (0.9)\end{aligned}$ & $\begin{array}{r}11(8.2) \\
11(8.2) \\
9(6.7) \\
0(0.0) \\
2(1.5) \\
0(0.0) \\
2(1.5) \\
3(2.2) \\
1(0.7)\end{array}$ & $\begin{array}{l}1(0.8) \\
4(3.4) \\
6(5.1) \\
2(1.7) \\
1(0.8) \\
0(0.0) \\
1(0.8) \\
0(0.0) \\
2(1.7)\end{array}$ & $\begin{aligned} & 5(3.3) \\
& 10(6.5) \\
& 6(3.9) \\
& 2(1.3) \\
& 2(1.3) \\
& 1(0.7) \\
& 5(3.3) \\
& 0(0.0) \\
& 7(4.6)\end{aligned}$ \\
\hline \multicolumn{7}{|c|}{ 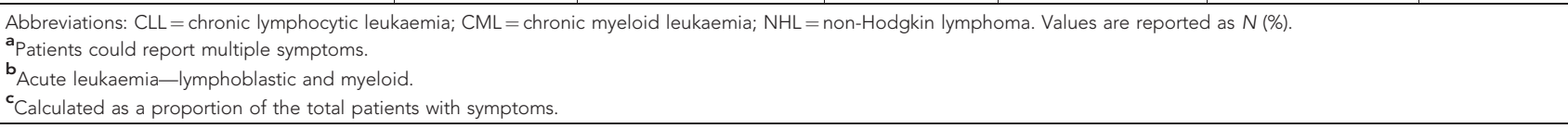 } \\
\hline
\end{tabular}


Table 3. Frequency of reported barriers to seeking help from the doctor

\begin{tabular}{|c|c|c|c|c|c|c|}
\hline & Total & Acute leukaemia ${ }^{a}$ & CLL & CML & Myeloma & NHL \\
\hline Total patients & $785(100)$ & $154(100)$ & $159(100)$ & $161(100)$ & $150(100)$ & $161(100)$ \\
\hline Total with symptoms & $654(83.3)$ & $141(91.6)$ & $108(67.9)$ & $134(83.2)$ & $118(78.7)$ & $153(95.0)$ \\
\hline Total with symptoms reporting reasons for putting off going to doctor & $380(58.1)$ & $96(68.1)$ & $39(36.1)$ & $121(90.3)$ & $51(43.2)$ & $73(47.7)$ \\
\hline \multicolumn{7}{|l|}{ Barrier $^{b, c}$} \\
\hline $\begin{array}{l}\text { Did not realise symptom was serious } \\
\text { Worried about wasting doctor's time } \\
\text { Too many other things to worry about } \\
\text { Too busy to go to doctor } \\
\text { Worried what doctor might find } \\
\text { Difficult to make appointment } \\
\text { Doctor difficult to talk to } \\
\text { Other }^{\text {d }}\end{array}$ & $\begin{array}{l}218(33.3) \\
43(6.6) \\
28(4.3) \\
26(4.0) \\
26(4.0) \\
16(2.4) \\
14(2.1) \\
9(1.4)\end{array}$ & $\begin{aligned} & 56(39.7) \\
& 17(12.0) \\
& 5(3.5) \\
& 5(3.5) \\
& 1(0.7) \\
& 6(4.3) \\
& 3(2.1) \\
& 3(2.1)\end{aligned}$ & $\begin{aligned} & 28(25.9) \\
& 3(2.8) \\
& 2(1.9) \\
& 1(0.9) \\
& 0(0.0) \\
& 2(1.9) \\
& 3(2.8) \\
& 0(0.0)\end{aligned}$ & $\begin{array}{l}63(47.0) \\
10(7.4) \\
12(8.9) \\
15(11.2) \\
15(11.2) \\
2(1.4) \\
2(1.4) \\
2(1.4)\end{array}$ & $\begin{aligned} 30 & (25.4) \\
4 & (3.4) \\
6 & (5.1) \\
3 & (2.5) \\
4 & (3.4) \\
1 & (0.8) \\
2 & (1.7) \\
1 & (0.8)\end{aligned}$ & $\begin{array}{l}41(26.8) \\
9(5.9) \\
3(2.0) \\
2(1.3) \\
6(3.9) \\
5(3.3) \\
4(2.6) \\
3(2.0)\end{array}$ \\
\hline \multicolumn{7}{|c|}{$\begin{array}{l}\text { Abbreviations: } \mathrm{CLL}=\text { chronic lymphocytic leukaemia; } \mathrm{CML}=\text { chronic myeloid leukaemia; } \mathrm{NHL}=\text { non-Hodgkin lymphoma. Values are reported as } \mathrm{N}(\%) \text {. } \\
{ }^{\mathrm{a}} \text { Acute leukaemia: lymphoblastic and myeloid. } \\
{ }^{b} \text { Categories are based on those validated in the Awareness and Beliefs about Cancer measure (Simon et al, 2012) and the Cancer Research UK Cancer Awareness Measure (Stubbings et al, } \\
\text { 2009). } \\
{ }^{c} \text { Percentages calculated as a proportion of the total patients with symptoms. } \\
{ }^{d} \text { Others: did not feel confident talking about symptoms with doctor }(n=6) \text {; too embarrassed to see doctor }(n=2) \text {; difficult to arrange transport }(n=1) \text {. }\end{array}$} \\
\hline
\end{tabular}

Table 4. Risk factors and time to presentation: patients waiting $>3$ months before presentation compared with those who did not

\begin{tabular}{|c|c|c|c|}
\hline & \multirow[b]{2}{*}{$\begin{array}{c}\text { Proportions waiting }>3 \text { months } \\
\text { before presentation (\%) }\end{array}$} & \multicolumn{2}{|c|}{ Relative risk for waiting $>3$ months before presentation } \\
\hline & & Unadjusted & $\begin{array}{l}\text { Adjusted for age, gender } \\
\text { and IMD quintile }\end{array}$ \\
\hline \multicolumn{4}{|l|}{ Symptoms } \\
\hline Unusually thirsty & $11 / 31(35.5)$ & 2.30 (1.38 to 3.83$)$ & 2.00 (1.12 to 3.58$)$ \\
\hline Skin itchy & $13 / 43(30.2)$ & $1.96(1.20$ to 3.21$)$ & 1.71 (0.93 to 3.13$)$ \\
\hline Unusual sweating at night & $40 / 137(29.2)$ & 2.26 (1.60 to 3.19$)$ & $2.13(1.45$ to 3.11$)$ \\
\hline Looking unusually pale & $22 / 87(25.3)$ & 1.69 (1.12 to 2.54$)$ & 1.60 (1.01 to 2.52$)$ \\
\hline Pain or discomfort in tummy & 24/100 (24.0) & 1.60 (1.07 to 2.39$)$ & 1.71 (1.13 to 2.57$)$ \\
\hline Unexpected weight loss & $26 / 114(22.8)$ & 1.52 (1.02 to 2.25$)$ & 1.36 (0.88 to 2.10$)$ \\
\hline Extreme fatigue or tiredness & 64/299 (21.4) & 1.78 (1.24 to 2.55$)$ & 1.58 (1.08 to 2.31$)$ \\
\hline Bleeding symptoms & $22 / 113(19.5)$ & 1.24 (0.81 to 1.89$)$ & $0.98(0.60$ to 1.61$)$ \\
\hline Shortness of breath & $31 / 159(19.5)$ & 1.27 (0.87 to 1.85$)$ & $1.17(0.77$ to 1.76$)$ \\
\hline Lots of coughs and colds & 16/88 (18.2) & $1.13(0.70$ to 1.83$)$ & $1.04(0.61$ to 1.76$)$ \\
\hline Pain or discomfort in bones & $30 / 167(18.0)$ & $1.13(0.77$ to 1.66$)$ & 0.99 (0.65 to 1.52$)$ \\
\hline Lump & 25/148 (16.9) & 1.04 (0.69 to 1.57$)$ & 1.07 (0.70 to 1.65$)$ \\
\hline Fever & $4 / 29(13.8)$ & $0.83(0.33$ to 2.11$)$ & $0.69(0.24$ to 2.05$)$ \\
\hline \multicolumn{4}{|c|}{ Reported barriers for not going to doctor } \\
\hline $\begin{array}{l}\text { Did not realise symptom } \\
\text { was serious }\end{array}$ & $51 / 210(24.3)$ & 1.93 (1.37 to 2.73$)$ & 1.84 (1.24 to 2.67$)$ \\
\hline
\end{tabular}

going to see a doctor. Patients with CML were most likely to report this $(n=32,24 \%)$, followed by CLL $(n=19,17 \%)$, NHL $(n=26$, $17 \%)$, myeloma $(n=18,15 \%)$ and acute leukaemia $(n=9,6 \%)$.

Risk factors for waiting $>\mathbf{3}$ months before presentation. With respect to symptom types across all diseases, the risk of waiting $>3$ months to first presentation for help seeking was significantly increased among those with unusual sweating at night, thirst, pain or discomfort in the tummy, pallor, extreme fatigue/tiredness; and these findings remained after adjusting for age, sex and deprivation (Table 4). Patients who did not think their symptom(s) were serious ( $n=51 / 210,24.3 \%$ ) were more likely to put off going to the doctor for $>3$ months (RR (adjusted) 1.84, 95\% CI 1.24-2.67).

\section{DISCUSSION}

Waiting $>3$ months before symptomatic presentation to a doctor occurred across the haematological malignancies included in this survey. This varied considerably by subtype, however, being relatively common in CML (24\% of patients) and less so in the acute leukaemias ( $10 \%$ of patients). Some symptoms were frequent across all diseases, particularly those that were systemic, such as fatigue. Other symptoms, however, were more specific to individual diseases, including pallor and bruising/bleeding in the acute leukaemias, abnormal lumps in CLL and NHL and bone pain in myeloma. The risk factors for waiting $>3$ months before seeking help varied by disease and symptom type, with many patients reporting that this occurred because they did not realise their symptoms were serious.

Few studies have examined symptoms prior to diagnosis of haematological malignancies. Those that have, have tended to use differing approaches, with some including blood parameters (e.g., anaemia), clinical signs (e.g., hepatosplenomegaly) and complications (e.g., renal failure), or predetermining symptom choices, while others did not. Studies examining time intervals preceding diagnosis are associated with similar inconsistencies, for example, in definitions of the time periods examined, the methods used and the way in which results are presented (Weller et al, 2012). 
With respect to symptoms, however, our findings are comparable with those of a recent UK study examining self-reported symptoms and time to diagnosis in $>3000$ patients with haematological malignancies (Howell et al, 2013). This study reported a similar pattern in the presence/absence of symptoms by disease subtype, patients with NHL being the most likely to have symptoms and patients with CLL the least. Further similarities existed, for example, in the frequency with which systemic symptoms (particularly fatigue) and pain were reported across all diseases and also the frequency that certain symptoms were reported by subtype (e.g., bleeding and bruising in acute leukaemia, lymphadenopathy in lymphoma and pain in myeloma). Overlap was also noted with findings of other studies examining CML, myeloma and CLL (Ong et al, 1995; Kariyawasan et al, 2007; Irfan and Bhurgri, 2009; Friese et al, 2011).

A number of recent studies have examined the positive predictive value of symptoms of haematological malignancies using GP records (Shephard et al, 2015a, b, c). Our findings are again largely comparable; with lymphadenopathy, for example, being common and strongly predictive of lymphoma. We presented a wider range of symptoms than those in the original paper by Forbes et al (2014) and identified those that were significantly associated with waiting $>3$ months before presentation - notably thirst, night sweats, pallor, abdominal pain and extreme fatigue.

With respect to time to presentation, a number of studies have examined this interval, although with various definitions and categorisations. Findings from the largest, most recent UK study found similar patterns to those reported here, with time to presentation (i.e., the patient interval) being longest for CML (33.5 days), followed by myeloma (31 days) and CLL ( 22 days); the acute leukaemias had shorter intervals (13-16 days), and the lymphomas varied markedly by subtype (9-30 days; Howell et al, 2013). Similarly, a further UK study found comparable results, though identified non-prompt presentation at 15 days (Keeble et al, 2014). Studies focusing solely on lymphoma showed variable average patient intervals (Summerfield et al, 2000; Allgar and Neal, 2005; Howell et al, 2006; Hansen et al, 2011), perhaps due to changes over time, but also due to the inclusion of different subtypes of lymphoma.

Strengths and weaknesses. The design and reporting system used in the study complied largely with the Aarhus Statement, ensuring consistency in definitions and methods and so comparability with future research examining prediagnostic pathways (Weller et al, 2012). Symptom categories were haematology specific and predetermined by clinical experts, thereby limiting options that could be selected to those commonly associated with the target diseases. Whilst this minimised the reporting of symptoms potentially unrelated to the haematological malignancy, it may also have inhibited the reporting of rarer or unusual symptoms, particularly among the lymphomas, where symptoms vary according to disease site(s).

This study differentiated between several haematological cancers, which effectively highlighted variations between these diseases; a characteristic often lost when subtypes are combined. NHLs were, however, considered collectively, combining multiple subtypes including those that are generally indolent (such as follicular and marginal zone lymphomas) with those that are more aggressive (such as diffuse large B-cell lymphoma). Similarly, acute lymphoid and myeloid leukaemias were grouped together, although patients with these cancer diseases have very different age profiles. Consequently, it is possible that variations between these disease categories may have been masked.

In addition, a number of subtypes were omitted from the sampling frame, one being the Hodgkin lymphomas. Although our previous work did not indicate that the symptoms associated with these diseases varied substantially from other lymphomas (Howell et al, 2013), it is possible that some differences may exist. Furthermore, the categorisation of prolonged delay (i.e., waiting $>3$ months before presentation) was identified in the original study as a marker for all cancers combined (Forbes et al, 2014). Use of this time point may not, therefore, be wholly appropriate in the context of haematological malignancies.

The present study has a number of limitations that may impact on generalisability, the first being that participants are considerably younger and more affluent than average for these diseases (Smith et al, 2011, 2015). Also, the sample of patients included in our study is derived from the NCPES; and the number of ethnic minority respondents to this survey was reported to be substantially less than the population as a whole (Department of Health, 2010). As a result, we cannot be sure our findings apply to those of non-White ethnic origin. The NCPES was also directed at people with in-patient/day-case episodes; and these patients may have had different characteristics/experiences than those treated wholly in the outpatient setting. Those receiving in-patient care, for example, may have had more aggressive or complex disease or been generally sicker than the patient population as a whole.

NCPES participants were also diagnosed at various time intervals prior to completion of the survey that, in common with many such studies using self-reported data, could lead to variation in their ability to remember events in the time leading to presentation and thus recall bias. Finally, the study targeted patients who had taken part in the NCPES (administered in the first quarter of 2010) who were still alive in November 2011, which may introduce survivor bias as the experiences of these people may be different from those of people dying before this time. Importantly, the early deaths may comprise a greater proportion of patients with later stage disease at diagnosis, possibly as a result of longer time to presentation/diagnosis, as well as those with more aggressive diseases, such as the acute leukaemias and some lymphomas.

Interpretation and implications for practice. 'Not realising symptom(s) were serious' was a clear risk factor for waiting $>3$ months before presentation and has been previously reported in patients with haematological malignancies (Howell et al, 2008). This may occur because many of the symptoms (e.g., fatigue, lymphadenopathy and bone pain), are common in the general population and often benign and self-limiting. Patients may justify such symptoms: fatigue may be considered a natural consequence of aging; lymphadenopathy may be attributed to localised infection (if around the neck) or a hernia (if in the groin); and bone pain to age-related 'wear and tear'. The same may occur for other rarer symptoms, such as genuine drenching night sweats, which might be attributed by women to expected menopausal symptoms. This process of 'normalising' symptoms has been reported in other studies and is thought to be associated with prolonged time to help seeking (Whitaker et al, 2014, 2015).

A further factor that may lead patients to conclude that their symptoms are not serious, and result in them waiting longer before seeking help, is the patients' expectations of what cancer might be like. For example, they may expect symptoms to be painful, constant, associated with a feeling of ill health and gradually becoming worse. However, a previous study of lymphoma (Howell et al, 2008) reported that patients often experienced abnormal lumps that were intermittent and painless and were not associated with feelings of ill health or progression; alternatively, patients also reported unexplained malaise, with no additional symptoms. These symptoms led patients to believe they had self-limiting, benign illnesses, rather than cancer. Also, despite some symptoms being indicative of individual subtypes, these may be varied and a clear 'symptom signature' (such as a breast lump in breast cancer) does not exist. There is also a lack of awareness about these diseases, and 
the range and combination of symptoms that may accompany them, among the general public (Howell et al, 2008).

Failure to recognise symptoms of cancer has been tackled in the past by campaigns such as Cancer Research UK's 'Be Clear on Cancer'. Although this approach may be more challenging for the diversely presenting haematological malignancies, this would be a useful first step in raising awareness of these complex cancers. Any such initiatives must, however, be balanced against finite resources and the reality that many people with symptoms will not, in fact, have cancer. Furthermore, it is important to recognise that haematological malignancies are diagnosed using an array of complex laboratory and clinical tests, and a simple first-line screening procedure, such as the PSA test used to identify potential prostate cancers, is not currently available.

The differences noted by subtype in the proportion of people waiting $>3$ months before presentation are unsurprising. Those with acute leukaemia are probably less likely to wait because onset of this disease is typically acute, progression and debility can occur rapidly and urgent medical intervention, often via emergency presentation, is required. The remaining diseases are generally more indolent in their onset and progression and ensuring early presentation in this group is more challenging.

The importance of avoiding prolonged time to diagnosis of haematological malignancies to ensure earlier stage of disease at diagnosis and also to accrue survival advantages is not as clear as it is for other cancers. It is likely that the tumour type and biology have greater impact on outcomes for some subtypes, than time to presentation. Acute leukaemias, for example, are usually associated with shortest waiting time before seeking help (as identified in this study, for the reasons stated above) but typically have poor survival compared with other subtypes. Longer time to presentation of indolent lymphoma, however, may have less impact on survival, as these diseases are not typically treated at the earliest opportunity postdiagnosis, but rather according to symptom burden. Also, patients with indolent lymphomas, for example, are often diagnosed with late-stage disease regardless of the time taken to seek help; these diseases are characterised by bone marrow involvement, which is automatically categorised at stage 4 . Despite this paradox, a definitive diagnosis is still required as early as possible so that treatment decisions can be made that are appropriate for the disease subtype. Furthermore, an excessive time period prior to diagnosis may result in end-organ damage (such as renal failure in myeloma and fractures), and the benefits of avoiding this are obvious.

Future research. Presentation to a doctor is just one aspect of the time taken to diagnose a haematological malignancy. The doctor must then recognise that the presenting symptoms could indicate a haematological malignancy and make timely and appropriate referrals into secondary care. Further research is needed, alongside primary care practitioners, to identify mechanisms by which patients can be identified as early as possible, and routes to haematology and diagnosis can be as seamless as possible.

\section{ACKNOWLEDGEMENTS}

We thank Quality Health for carrying out the fieldwork, the Department of Health for managing the project and Hamish Ross for advice on the symptom list. We thank Macmillan Cancer Support and the patients for taking part in the cognitive testing. The original study: 'Risk factors for delay in presentation' was carried out by the Policy Research Unit in Cancer Awareness, Screening and Early Diagnosis as part of its research programme. This unit receives funding from the Department of Health Policy Research Programme and is a collaboration between researchers from seven institutions (Queen Mary University of London,
University College London, Kings College London, London School of Hygiene and Tropical Medicine, Hull York Medical School, Durham University and Peninsula Medical School). This work was funded by the Policy Research Unit in Cancer Awareness, Screening and Early Diagnosis, the National Cancer Action Team/Department of Health and Cancer Research UK. Preparation of the present report was supported by Leukaemia Lymphoma Research (LLR).

\section{REFERENCES}

Allgar VL, Neal RD (2005) Delays in the diagnosis of six cancers: analysis of data from the National Survey of NHS Patients: Cancer. $\mathrm{Br} J$ Cancer 92: 1959-1970.

Department of Health (2000) The NHS Cancer plan: a plan for investment, a plan for reform.

Department of Health (2010) National Survey Report: National Cancer Patient Experience Survey Programme.

Department of Health (2011a) Improving Outcomes: a Strategy for Cancer. Department of Health (2011b) National Audit of Cancer Diagnosis in Primary Care. Elliss-Brookes L, McPhail S, Ives A, Greenslade M, Shelton J, Hiom S, Richards M (2012) Routes to diagnosis for cancer - determining the patient journey using multiple routine data sets. Br J Cancer 107: 1220-1226.

Ferlay J, Shin H-R, Bray F, Forman D, Mathers C, Parkin DM (2010) Estimates of worldwide burden of cancer in 2008: GLOBOCAN 2008. Int J Cancer 127: 2893-2917.

Forbes LJL, Warburton F, Richards MA, Ramirez AJ (2014) Risk factors for delay in symptomatic presentation: a survey of cancer patients. Br J Cancer 111: $581-588$.

Friese CR, Earle CC, Magazu LS, Brown JR, Neville BA, Hevelone ND, Richardson LC, Abel GA (2011) Timeliness and quality of diagnostic care for medicare recipients with chronic lymphocytic leukemia. Cancer 117: 1470-1477.

Hansen RP, Vedsted P, Sokolowski I, Søndergaard J, Olesen F (2011) Time intervals from first symptom to treatment of cancer: a cohort study of 2,212 newly diagnosed cancer patients. BMC Health Serv Res 11: 284.

Howell DA, Smith AG, Jack A, Patmore R, Macleod U, Mironska E, Roman E (2013) Time-to-diagnosis and symptoms of myeloma, lymphomas and leukaemias: a report from the Haematological Malignancy Research Network. BMC Hematol 13: 9.

Howell DA, Smith AG, Roman E (2006) Lymphoma: variations in time to diagnosis and treatment. Eur J Cancer Care (Engl) 15: 272-278.

Howell DA, Smith AG, Roman E (2007) Referral pathways and diagnosis: UK government actions fail to recognize complexity of lymphoma. Eur $J$ Cancer Care (Engl) 16: 529-532.

Howell DA, Smith AG, Roman E (2008) Help-seeking behaviour in patients with lymphoma. Eur J Cancer Care (Engl) 17: 394-403.

Irfan SM, Bhurgri Y (2009) Clinico-pathological features and outcomes in chronic phase chronic myeloid leukemia patients treated with hydroxyurea. Asian Pac J Cancer Prev 10: 591-594.

Jemal A, Siegel R, Ward E, Hao Y, Xu J, Murray T, Thun MJ (2008) Cancer Statistics, 2008. CA Cancer J Clin 58: 71-96.

Kariyawasan CC, Hughes DA, Jayatillake MM, Mehta AB (2007) Multiple myeloma: causes and consequences of delay in diagnosis. QJM 100: 635-640.

Keeble S, Abel GA, Saunders CL, McPhail S, Walter FM, Neal RD, Rubin GP, Lyratzopoulos G (2014) Variation in promptness of presentation among 10,297 patients subsequently diagnosed with one of 18 cancers: evidence from a National Audit of Cancer Diagnosis in Primary Care. Int J Cancer 135: $1220-1228$.

Lyratzopoulos G, Neal RD, Barbiere JM, Rubin GP, Abel GA (2012) Variation in number of general practitioner consultations before hospital referral for cancer: findings from the 2010 National Cancer Patient Experience Survey in England. Lancet Oncol 13: 353-365.

Macleod U, Mitchell ED, Burgess C, Macdonald S, Ramirez AJ (2009) Risk factors for delayed presentation and referral of symptomatic cancer: evidence for common cancers. Br J Cancer 101(Suppl 2): S92-S101.

McPhail S, Elliss-Brookes L, Shelton J, Ives A, Greenslade M, Vernon S, Morris EJA, Richards M (2013) Emergency presentation of cancer and short-term mortality. Br J Cancer 109: 2027-2034.

Neal RD, Din NU, Hamilton W, Ukoumunne OC, Carter B, Stapley S, Rubin G (2014) Comparison of cancer diagnostic intervals before and after 
implementation of NICE guidelines: analysis of data from the UK General Practice Research Database. Br J Cancer 110: 584-592.

NICE (2005) Referral Guidelines for Suspected Cancer. Department of Health: London, UK.

Ong F, Hermans J, Noordijk EM, Wijermans PW, Kluin-Nelemans JC (1995) Presenting signs and symptoms in multiple myeloma: high percentages of stage III among patients without apparent myeloma-associated symptoms. Ann Hematol 70: 149-152.

Peacock O, Clayton S, Atkinson F, Tierney GM, Lund JN (2013) 'Be Clear on Cancer': the impact of the UK National Bowel Cancer Awareness Campaign. Colorectal Dis 15: 963-967.

Public Health Observatory (2011) Summary IMD 2010 scored for non-LSOA geographies. Availabe at http://www.apho.org.uk/resource/item.aspx?RID=111280, (last accessed 23 March 2012).

Ramirez A, Westcombe A, Burgess C, Sutton S, Littlejohns P, Richards M (1999) Factors predicting delayed presentation of symptomatic breast cancer: a systematic review. Lancet 353: 1127-1131.

Richards MA (2009) The size of the prize for earlier diagnosis of cancer in England. Br J Cancer 101: S125-S129.

Richards MA, Smith P, Ramirez AJ, Fentiman IS, Rubens RD (1999) The influence on survival of delay in the presentation and treatment of symptomatic breast cancer. Br J Cancer 79: 858-864.

Shephard EA, Neal RD, Rose P, Walter FM, Litt EJ, Hamilton WT (2015a) Quantifying the risk of multiple myeloma from symptoms reported in primary care patients: a large case-control study using electronic records. Br J Gen Pract 65: e106-e113.

Shephard EA, Neal RD, Rose PW, Walter FM, Hamilton WT (2015b) Quantifying the risk of Hodgkin lymphoma in symptomatic primary care patients aged $\geqslant 40$ years: a case-control study using electronic records. Br J Gen Pract 65: e289-e294.

Shephard EA, Neal RD, Rose PW, Walter FM, Hamilton WT (2015c) Quantifying the risk of non-Hodgkin lymphoma in symptomatic primary care patients aged $\geqslant 40$ years: a large case-control study using electronic records. Br J Gen Pract 65: e281-e288.

Simon AE, Forbes LJL, Boniface D, Warburton F, Brain KE, Dessaix A, Donnelly M, Haynes K, Hvidberg L, Lagerlund M, Petermann L, Tishelman C, Vedsted P, Vigmostad MN, Wardle J, Ramirez AJ (2012) An international measure of awareness and beliefs about cancer: development and testing of the ABC. BMJ Open 2: e001758.
Smith A, Crouch S, Lax S, Li J, Painter D, Howell D, Patmore R, Jack A, Roman E (2015) Lymphoma incidence, survival and prevalence 2004-2014: sub-type analyses from the UK/'s Haematological Malignancy Research Network. Br J Cancer 112: 1575-1584.

Smith A, Howell D, Patmore R, Jack A, Roman E (2011) Incidence of haematological malignancy by sub-type: a report from the Haematological Malignancy Research Network. Br J Cancer 105: 1684-1692.

Stubbings S, Robb K, Waller J, Ramirez A, Austoker J, Macleod U, Hiom S, Wardle J (2009) Development of a measurement tool to assess public awareness of cancer. Br J Cancer 101: S13-S17.

Summerfield GP, Carey PJ, Galloway MJ, Tinegates HN (2000) An audit of delays in diagnosis and treatment of lymphoma in district hospitals in the northern region of the United Kingdom. Clin Lab Haematol 22: 157-160.

Swerdlow SH, Campo E, Harris NL, Jaffe ES, Pileri SA, Stein H, Thiele J, Vardiman J (2008) WHO Classification of Tumours of Haematopoietic and Lymphoid Tissues, 4th edn. International Agency for Research on CancerLyon, France.

Weller D, Vedsted P, Rubin G, Walter FM, Emery J, Scott S, Campbell C, Andersen RS, Hamilton W, Olesen F, Rose P, Nafees S, van Rijswijk E, Hiom S, Muth C, Beyer M, Neal RD (2012) The Aarhus statement: improving design and reporting of studies on early cancer diagnosis. $\mathrm{Br} J$ Cancer 106: 1262-1267.

Westlake S (2008) Cancer incidence and mortality in the United Kingdom and constituent countries, 2003-05. Health Stat Q 40: 91-97.

Whitaker KL, Macleod U, Winstanley K, Scott SE, Wardle J (2015) Help seeking for cancer 'alarm' symptoms: a qualitative interview study of primary care patients in the UK. Br J Gen Pract 65: e96-e105.

Whitaker KL, Scott SE, Winstanley K, Cromme S, Macleod U, Wardle J (2014) The association between normalising attributions and help-seeking for cancer alarm symptoms in the community: a cross-sectional survey. Lancet 384(Supplement 2): S86.

(c) (i)(2) (2) This work is licensed under the Creative Commons cc) national License. To view a copy of this license, visit http:// creativecommons.org/licenses/by-nc-sa/4.0/ 